\title{
Urine proteomes of healthy aging humans reveal extracellular matrix (ECM) alterations and immune system dysfunction
}

\author{
M. Bakun • G. Senatorski • T. Rubel • A. Lukasik • \\ P. Zielenkiewicz • M. Dadlez • L. Paczek
}

Received: 5 February 2013 / Accepted: 1 July 2013 / Published online: 6 August 2013

(C) The Author(s) 2013. This article is published with open access at Springerlink.com

\begin{abstract}
Aging is a complex physiological process that poses considerable conundrums to rapidly aging societies. For example, the risk of dying from cardiovascular diseases and/or cancer steadily declines for people after their $60 \mathrm{~s}$, and other causes of death predominate for seniors older than 80 years of age. Thus, physiological aging presents numerous unanswered
\end{abstract}

M Bakun and G Senatorski contributed equally to this work.

Electronic supplementary material The online version of this article (doi:10.1007/s11357-013-9562-7) contains supplementary material, which is available to authorized users.

M. Bakun • M. Dadlez

Mass Spectrometry Laboratory, Institute of Biochemistry and Biophysics, Polish Academy of Sciences, ul. Pawinskiego 5a, 02-106 Warsaw, Poland

\section{G. Senatorski $\cdot$ L. Paczek $(\bowtie)$}

Department of Immunology, Transplantology and Internal Diseases, Transplantation Institute,

Medical University of Warsaw,

ul. Nowogrodzka 59, 02-006 Warsaw, Poland

e-mail: leszek.paczek@wum.edu.pl

T. Rubel

Institute of Radioelectronics,

Warsaw University of Technology,

ul. Nowowiejska 15/19, 00-665 Warsaw, Poland

\section{A. Lukasik • P. Zielenkiewicz}

Bioinformatics Department, Institute of Biochemistry

and Biophysics, Polish Academy of Sciences,

ul. Pawinskiego 5a, 02-106 Warsaw, Poland

\section{Dadlez}

Department of Biology, Warsaw University, ul. Miecznikowa 1, 02-096 Warsaw, Poland questions, particularly with regard to changing metabolic patterns. Urine proteomics analysis is becoming a non-invasive and reproducible diagnostic method. We investigated the urine proteomes in healthy elderly people to determine which metabolic processes were weakened or strengthened in aging humans. Urine samples from 37 healthy volunteers aged 19-90 years (19 men, 18 women) were analyzed for protein expression by liquid chromatography-tandem mass spectrometry. This generated a list of 19 proteins that were differentially expressed in different age groups (young, intermediate, and old age). In particular, the oldest group showed protein changes reflective of altered extracellular matrix turnover and declining immune function, in which changes corresponded to reported changes in cardiovascular tissue remodeling and immune disorders in the elderly. Thus, urinary proteome changes in the elderly appear to reflect the physiological processes of aging and are particularly clearly represented in the circulatory and immune systems. Detailed identification of "protein trails" creates a more global picture of metabolic changes that occur in the elderly.

Keywords Aging · Extracellular matrix alterations . Mass spectrometry $\cdot$ Immune system dysfunction . Proteomics. Urine proteome

\section{Introduction}

Aging is a complex physiological process that poses many problems and conundrums for rapidly aging societies. For example, the risk of dying from cardiovascular 
diseases and/or cancer steadily declines for people after their $60 \mathrm{~s}$, and in seniors older than 80 years of age, other causes of death are predominant (de los Campos et al. 2012). Thus, diagnoses and research in which heart disease and cancer are the focus are ineffectual for half of the patients older than 80 years, and physiological aging raises many unanswered questions, particularly with regard to changing metabolic patterns.

Urine proteomics has become a non-invasive, reproducible, and easy-to-frequent repetition diagnostic method. In this study, we show that there are urine proteome changes with age in healthy humans and that this may be useful for understanding certain pathogenic processes in aging. This investigation was based on the following considerations.

\section{Fluid biopsy}

Urine proteome analysis is a rapidly developing analytical tool that is aimed at establishing new, noninvasive "fluid biopsy" diagnostic methods for renal and urinary tract diseases (Tyan et al. 2006; Varghese et al. 2007). Although this methodology is still in its infancy, knowledge on urine proteomes in health and disease is growing rapidly due to advancements in instrumentation, data analysis techniques, and the relative ease of acquiring clinically relevant samples. Thus, urinary proteome analysis is the subject of a rapidly growing number of studies, and this topic is often reviewed (Pisitkun et al. 2006).

Numerous potential markers for different pathologies, not only for the kidney, but also for the urinary tract, vascular system, and other organs, have been found (van Eyk and Dunn 2008). For example, the urine proteomes of small cohorts of patients studied by capillary electrophoresis coupled with mass spectrometry have established potential markers for ADPKD (Pavik et al. 2012; Kistler et al. 2009). The first urine proteomic study was done in 1979 using 2-D PAGE electrophoresis (Anderson et al. 1979). Later, numerous hybrid techniques were used for different diseases (including uronephrological cases), such as MALDI-TOF, SELDI-TOF, CE-MS/MS, and LC-ESI-TOF-MS/M (M'Koma et al. 2007; Mosley et al. 2006; Tyan et al. 2006; Julian et al. 2007). Depending on the methodology used, the number of detected proteins can vary greatly from 200 to 2,500 (Pisitkun et al. 2006; Weissinger et al. 2004; Barratt and Topham 2007). Thus, urine proteomics may provide a more "global view" of underlying physiological processes that are not necessarily disease specific.

Consequences of aging in general

Aging influences many biological processes (vB Hjelmborg et al. 2006). Changes in these processes are directed by several guiding physiologic principles: diminished flexibility (Lipsitz and Goldberger 1992), as manifested for example by less variable heart rate responses; changes in circadian patterns (Veldhuis 1997); and a loss of physiologic reserves required to cope with challenges to homeostasis (Cowdry 1942). While the progression of certain biological changes is linear over time, such as graying of hair, reduced skin elasticity, and vascular aging, other biological variables, such as lung capacity and sensory and cognitive functions, do not always correlate with chronological age (Bulpitt et al. 1994). Aging changes progress in a nonuniform manner, and organs age at different rates and are influenced by many factors, including genetics, lifestyle, environmental factors, and a general loss of functional reserves (vB Hjelmborg et al. 2006).

In the elderly, these progressive changes result in increased susceptibility to numerous diseases (Martin and Sheaff 2007). For example, with age, the renal mass tends to become smaller and function declines. The older kidney is more prone to nephrotoxicity related to medications (Michel and Kelly 1998) or application of intravenous contrast dye (Rich and Crecelius 1990). However, much of the research on age-related changes in humans has focused on particular disease processes, in which processes are often quite complex (e.g., cardiovascular disease, immunological disorders) and are affected by numerous factors wholly unrelated to human aging. Thus, more investigations are needed on "normal aging" in humans to determine which physiological processes are most affected by this natural chronological phenomenon.

Currently, more and more studies are using urinary proteome analysis applied to clinical research. The results have often been distant from what was expected, probably due to the presence of proteins/peptides whose levels change significantly with aging. More basic research on the effects of factors unrelated to disease, such as aging, on urine proteomes may aid in selecting control groups for clinical trials. More importantly, a more global view of urine proteome changes with human aging may highlight previously unexpected physiological changes. Thus, we investigated if urine proteomes 
changed significantly in healthy elderly people and if these would highlight metabolic processes that weakened or strengthened in aging humans.

\section{Material and methods}

Urine samples

Urine samples were collected from 37 healthy volunteers aged 19-90 years (19 men and 18 women). The exclusion criteria included the following: current infection of the urinary tract, macroscopic hematuria, diabetes mellitus, malignancy of the urinary tract or generalized malignancy of another system, post-organ transplantation status, and current pregnancy.

Study protocol was approved by our local ethics committee. Informed consent was obtained from all participants. This study was performed in accordance with the Declaration of Helsinki Principles.

Urine collection

Samples were collected from the 37 healthy donors using a uniform protocol. The second or third morning midstream urine was collected from all participants at 1 and $3 \mathrm{~h}$ after previous micturition. Sterile urine containers were used to collect samples. Sample pH was stabilized at 7.2 by adding one tenth of the volume of 1 M HEPES (pH 7.2) immediately after collection. Further sample preparation steps were carried out within $1 \mathrm{~h}$ after collection during which time the sample was kept at room temperature. Samples were vortexed for $2 \mathrm{~min}$, centrifuged ( $3000 \times \mathrm{g}$, room temperature) for $10 \mathrm{~min}$ to clear debris, filtered through a $0.4-\mu \mathrm{m}$ filter (Rotilabo-Spritzenfilter, P819.1, Roth), and separated into $1-\mathrm{ml}$ aliquots. Sample aliquots were stored at $-80{ }^{\circ} \mathrm{C}$ for later use.

\section{Sample filtration}

Membrane filters with a $10 \mathrm{kDa}$ cutoff (Amicon Ultra0.5, UFC501096, Millipore) were washed twice with MilliQ water prior to use. Urine was centrifuged through the membrane at $14,000 \times g$ for $15 \mathrm{~min}$. Next, $500 \mu \mathrm{l}$ of MQ was added to the retentate and centrifugation was repeated. To recover a concentrated and desalted sample, the filter was placed upside down in a clean microtube and centrifuged for $2 \mathrm{~min}$ at $1,000 \times \mathrm{g}$. Protein concentration was determined by the Bradford method. Samples aliquots were stored in siliconized microtubes (Sigma-Aldrich) at $-80{ }^{\circ} \mathrm{C}$ for later use.

Urine proteome preparation

A total of $4 \mu \mathrm{g}$ of protein from each sample was diluted in $100 \mathrm{mM} \mathrm{NH}_{4} \mathrm{HCO}_{3}$ to a final volume of $10 \mu \mathrm{l}$. DTT $(100 \mathrm{mM})$ was added to a sample for a final concentration of $10 \mathrm{mM}$ and incubated at $56{ }^{\circ} \mathrm{C}$ for $40 \mathrm{~min}$. To block reduced cysteines, $0.5 \mathrm{M}$ iodoacetamide at a final concentration of $50 \mathrm{mM}$ was added, and the sample was incubated at room temperature for $30 \mathrm{~min}$ in the dark. Trypsin (Promega) was added at a 1:20 v/v ratio and incubated at $37{ }^{\circ} \mathrm{C}$ overnight. Finally, trifluoroacetic acid was added to digested protein samples to reduce the $\mathrm{pH}$ to 2 and inactivate trypsin. Resulting peptides were analyzed by liquid chromatography-tandem mass spectrometry (LC-MS/MS) for peptide identification and LC-MS for relative quantitation. Data were acquired in separate experiments as described below.

\section{LC-MS settings}

LC-MS proteomic analyses of urine samples used a LTQ-Orbitrap Velos mass spectrometer (Thermo Scientific) coupled with a nanoACQUITY (Waters Corporation) LC system. Spectrometer parameters were as follows: polarity mode, positive; and capillary voltage, $1.5 \mathrm{kV}$. A sample was first applied to the nanoACQUITY UPLC Trapping Column (Waters) using water containing $0.1 \%$ formic acid as the mobile phase. Next, the peptide mixture was transferred to the nanoACQUITY UPLC BEH C18 Column (Waters, 75- $\mu \mathrm{m}$ inner diameter; 250-mm long) using an acetonitrile gradient (5-35\% acetonitrile over $160 \mathrm{~min}$ ) in the presence of $0.1 \%$ formic acid with a flow rate of $250 \mathrm{nl} / \mathrm{min}$ and eluted directly to the ion source of the mass spectrometer. Each LC run was preceded by a blank run to ensure that there was no carry-over of material from the previous analysis.

Qualitative analyses (i.e., peptide and protein identification) used pooled urine samples in data-dependent MS-to-MS/MS acquisition mode. Collision-induced dissociation was used, and up to five MS/MS processes were allowed for each MS scan. To increase the numbers of peptide identifications, three LC-MS/MS runs were performed per pooled sample, with each covering one of three $m / z$ value ranges: $300-600,500-900$, and 
$800-2,000$. This approach substantially improved the coverage for protein identification.

Quantitative analyses for individuals used separate survey scan LC-MS runs with an $\mathrm{m} / \mathrm{z}$ measurement range of 300-2,000 using the same acetonitrile gradient as for qualitative LC-MS/MS runs. The data-dependent MS-to-MS/MS switch was disabled, and the spectrometer resolution was set to 15,000 .

Qualitative MS data processing and database search

The acquired MS/MS raw data files were processed to produce peak lists with Mascot Distiller software (version 2.2.1, Matrix Science). The resulting ion lists were searched using the Mascot search engine (version 2.2.03, Matrix Science) against a database comprising all human protein entries from the SwissProt database $(20,273$ sequences) and their reversed versions. The search parameters were as follows: enzyme specificity, semitrypsin; fixed modification, carbamidomethylation (C); variable modifications, oxidation (M) and carbamidomethylation $(\mathrm{K})$; and protein mass, unrestricted. The peptide and fragment ion mass tolerances (6 ppm and $0.4 \mathrm{Da}$, respectively) were established separately for individual LC-MS/MS runs using a procedure involving two database searches separated by a mass measurement error recalibration step, as previously described in Mikula et al. (2010).

Mascot search result processing used MScan, a proprietary software tool implemented in the Java programming language (http://proteom.ibb.waw.pl/). The statistical significance of peptide identifications was assessed using a joined target/decoy database search approach and a procedure that provided $q$-value estimates for each peptide spectrum match (PSMs) in the data set (Mikula et al. 2010; Käll et al. 2008). Only PSMs with $q$-values of $\leq 0.01$ and proteins represented by at least two peptides were regarded as confidently identified. Proteins identified by a subset of peptides from another protein were excluded from analysis, and proteins matching the same set of peptides were clustered into single groups.

\section{Quantitative MS data processing}

Peptide identifications from all LC-MS/MS runs were merged into a common list, which was next overlaid onto 2-D maps generated from the LC-MS profile data of individual samples. A more detailed description of the feature extraction procedure was previously reported (Bakun et al. 2009). Briefly, the list of identified peptides was used to tag the corresponding peptide-related ion spectra based on $\mathrm{m} / \mathrm{z}$ differences, deviations from the predicted elution times, and the match between the theoretical and observed isotopic envelopes. The maximum deviation accepted in $\mathrm{m} / \mathrm{z}$ and retention time were established separately for each of the processed LC-MS spectra, in order to take into account possible variations in mass measurement accuracy and chromatographic separation between runs. First, an initial search with wide tolerances ( $\pm 25 \mathrm{ppm}$ and $\pm 10 \mathrm{~min}$, respectively, for $m / z$ and RT) and restrictive parameters of isotopic envelope fits (at least four peaks detected, coefficient of determination $\geq 0.95$ ) was performed. Next, non-linear mass and time calibration function were calculated using locally weighted regression smoother (LOESS), and the search was repeated with narrowed tolerances and relaxed fit requirements. The mean values of the estimated tolerances in this study were equal to $\pm 17 \mathrm{ppm}$ and $\pm 6 \mathrm{~min}$. Finally, the relative abundances of peptide ions were determined as the heights of 2-D fits to the most prominent peaks of the tagged isotopic envelopes.

After the quantitative feature extraction step, a filter was applied to the data set to remove peptide ions with missing values in $>20 \%$ of the samples. To avoid removing strictly differential peptides (i.e., detected or missing only in one of the studied groups of samples), a $\chi^{2}$ statistic was used to assess significant inequalities in the distribution of missing values in the groups of samples. Next, a modified $k$-nearest neighbors procedure was used to impute the remaining missing values. The applied modifications included the use of variable-size neighborhoods and correlationbased metrics rather than Euclidean distances.

To minimize the effects of non-biological sources of variation, log-transformed peptide abundances were normalized by fitting a robust LOESS between individual samples and a median pseudo-sample. The parameters for the fit were established using a set of features that exhibited low variance in the non-normalized data and then applied to the whole data set. Finally, the normalized peptide-level data were rolled up to relative protein abundances. The procedure used involved rescaling abundances of peptides that originated from the same protein to a common level, followed by computing their median value. 
Statistical analysis of quantitative MS results

To select differentially expressed proteins, we used a nonparametric ANOVA-based resampling statistical test. The resulting $p$ values were then corrected for multiplehypothesis testing using a two-step Benjamini-Hochberg procedure that controlled for the false discovery rate (Benjamini and Hochberg 1995). Relative protein abundances with adjusted $p$ values $\leq 0.05$ and fold-change (FC) values $\geq 1.5$ were considered as significantly changed in at least one of the studied groups.

For graphical summaries and to evaluate the relationships among the studied samples, we used principal component analysis and Ward's linkage hierarchical clustering. All statistical analyses used proprietary software running in the MATLAB (MathWorks) environment (MStat, available at http://proteom.ibb.waw.pl/).

\section{Results}

Second morning urine samples were collected from 37 healthy volunteers aged 19-90 in the Clinical Hospital of Medical University of Warsaw. The protein fractions obtained after filtration, reduction, alkylation, and trypsin cleavage (described in "Materials and methods") were appropriately aliquoted to avoid multiple freeze-thaw cycles and stored at $-80{ }^{\circ} \mathrm{C}$ until use.

\section{Protein identification}

LC-MS/MS measurements of pooled urine samples were conducted for protein identification, resulting in the acquisition of 18,336 MS/MS spectra. A search against the SwissProt database using the Mascot engine confidently identified a set of 2,714 peptides with an estimated false discovery rate of 0.01 (Supplementary Table S1). In total, 578 proteins were identified, of which 257 were represented by at least two peptides (Supplementary Table S2).

\section{Quantitative analysis}

To obtain quantitative information, $0.5 \mu \mathrm{g}$ protein of each of the 37 samples was subjected to LC-MS analysis. The samples were assigned to three separate groups, according to the age distribution of our study subjects (Fig. 1): age range 19-26 (average 21, 13 samples), age range 45-54 (average 49, 12 samples), and age range 72-90 (average 79, 12 samples). Demographic characteristics and renal function results for the three age groups (further referred as, respectively, AVG_21, AVG_49, and AVG_79) are summarized in Table 1.

Label-free quantitative analysis was based on unique peptides (i.e., peptides unambiguously assigned to proteins) with confident MS/MS identifications. Proteins represented by at least two such peptides were quantified after overlying the qualitative information obtained from LC-MS/MS runs onto the LC-MS spectra of individual samples (see "Material and methods"). The resulting relative peptide and protein abundances are supplied in supplementary materials (Supplementary Tables S3 and S4).

Further statistical analyses were conducted using a resampling ANOVA-based test. Only proteins with corresponding $p$ values $\leq 0.05$ (after the adjustment for multiple-hypothesis testing) and $\mathrm{FC}$ values $\geq 1.5$ were deemed significant. A simultaneous comparison of all studied groups, followed by three pair-wise comparisons of individual groups, resulted in the selection of 24 age-related proteins (Table 2). The largest set, consisting of 22 proteins, differentiated the two extreme age groups: AVG_21 and AVG_79. Of them, 8 showed increased abundance in the AVG_79 group, while the levels of the remaining 14 proteins were lower in this group. The comparison of the AVG_49 group and the AVG_79 group revealed nine differential proteins. Seven of these proteins were in common with those selected in the previous comparison and exhibited a consistent directionality of changes with respect to the AVG_79 group in both comparisons (Table 2 and Fig. 2). Under the applied threshold of significance, no differentially expressed proteins were identified in the last pair-wise comparison, involving AVG_21 and AVG_49 groups.

The results of the statistical tests indicate that the observed differential expression can be mostly attributed to large changes in protein levels between the two extreme groups. This statement is also supported by the results of hierarchical clustering (Fig. 3) and principal component analysis (Supplementary Figure 1). In both cases, only the samples belonging to AVG_21 and AVG_79 groups are well separated, while AVG_49 samples tend to cluster with those of younger people.

Due to limited access to informed consent samples, no confirmatory sample set could be extracted, and the necessary confirmation step assuming the use of an 


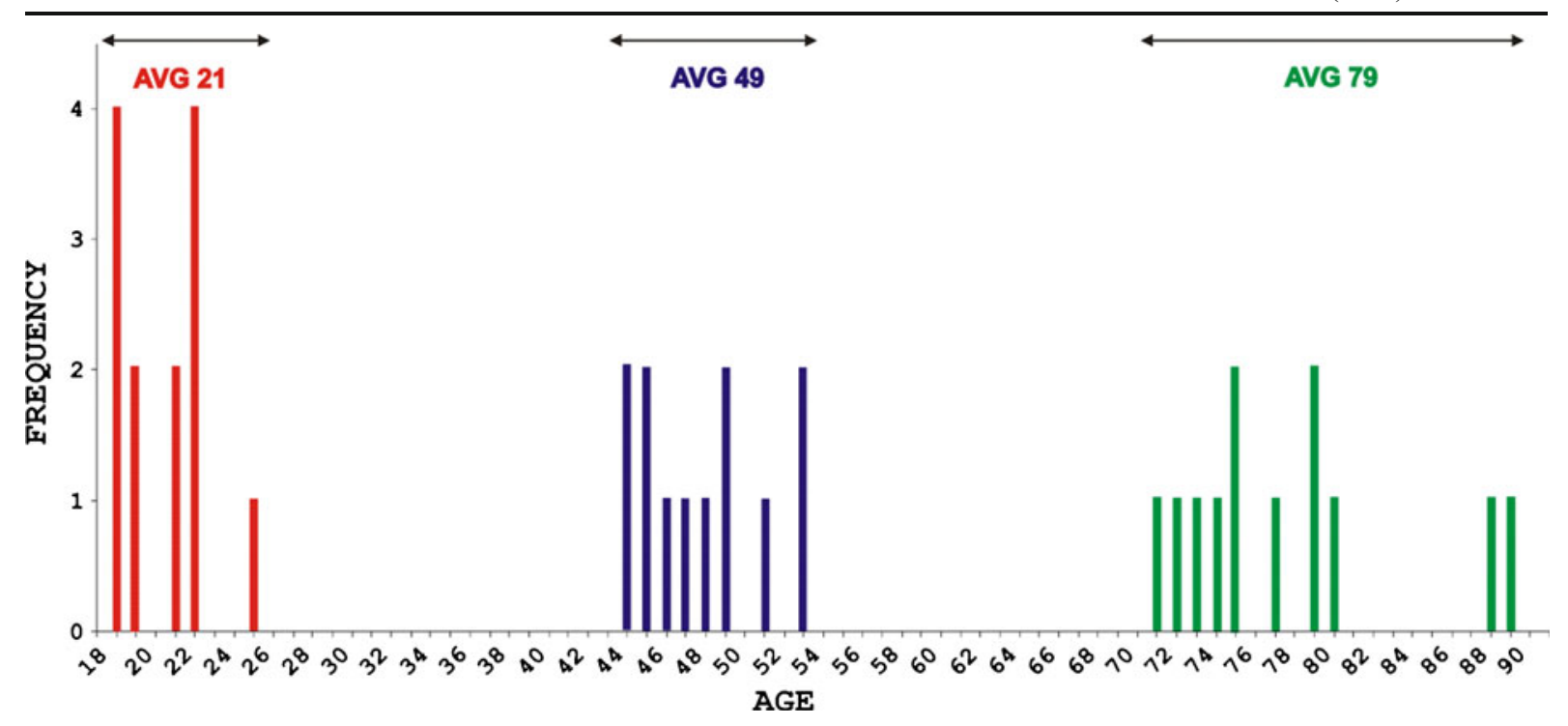

Fig. 1 Three sample groups established according to the age distribution of the 37 healthy volunteers participating in the study: AVG 21 (range, 19-26 years; mean, 21), AVG_49 (range, 45-54 years; mean, 49), and AVG_79 (range, 72-90 years; mean, 79)

independent set of samples could not be carried out within the frame of the present study. Lack of such confirmatory data set is a shortcoming of the present study.

\section{Discussion}

Our analysis of the urine proteomes of 37 healthy volunteers of both sexes divided into three discontinuous age groups (Table 1) revealed 24 proteins that differentiated between the age groups of 21 years (range, 19-26 years), 49 years (range, 45-54 years), and 79 years (range, $72-90$ years) (Table 2). Of them, 22 proteins were differentially expressed in the urine proteome of the youngest group compared with that of the oldest group, and 9 proteins were differentially

Table 1 Demographic characteristics and renal function of three study groups

\begin{tabular}{llll}
\hline & AVG_21 & AVG_49 & AVG_79 \\
\hline$n$ & 13 & 12 & 12 \\
$\mathrm{M} / \mathrm{F}$ & $7 / 6$ & $6 / 6$ & $6 / 6$ \\
Age (years) & $21 \pm 2$ & $49 \pm 3$ & $79 \pm 6$ \\
GFR (ml/min/1.73 m $\left.{ }^{2}\right)$ & $112 \pm 9$ & $100 \pm 39$ & $83 \pm 13$ \\
Serum creatinine $(\mu \mathrm{mol} / \mathrm{l})$ & $68 \pm 9$ & $69 \pm 19$ & $70 \pm 15$ \\
CRP & $2 \pm 1$ & $2 \pm 1$ & $2 \pm 2$ \\
\hline
\end{tabular}

expressed in the intermediate age group compared with the oldest group.

The profiles of the proteins that differed in the elderly included those involved in tissue remodeling processes, increased likelihood of coagulation and fibrinolysis, low-grade inflammation, and immune and metabolic dysregulation. These changes are in keeping with the observed increases in incidence with age of cardiovascular diseases, autoimmune diseases, and metabolic disorders. They are also in line with current understanding of the pathophysiology of tissue remodeling, prothrombotic status, and the occurrence of low-grade inflammation in the elderly (Meyer et al. 1998) and ageassociated dysregulation of immune system function (Yao et al. 2011) and autoimmune disease.

Our major findings come under the following broad categories.

Tissue remodeling

We found increased expression of peptidase inhibitor 16 (PI16) in the urine proteome in our group of clinically healthy elderly people who were free of chronic diseases, current infections, inflammatory disorders, and malignancies as compared to the youngest and intermediate age groups. These elderly people also had reduced expressions of EGF-containing fibulin-like extracellular matrix protein 2 and secreted protein acidic and rich in cysteine (SPARC). These changes are consistent with 
Table 2 Differentially expressed proteins in urine proteomes based on statistical analysis of three age groups

\begin{tabular}{|c|c|c|c|c|c|c|c|}
\hline \multirow[t]{2}{*}{ SwissProt ACC } & \multirow[t]{2}{*}{ Protein name } & \multicolumn{2}{|c|}{ AVG_49 vs. AVG_21 } & \multicolumn{2}{|c|}{ AVG_79 vs. AVG_49 } & \multicolumn{2}{|c|}{ AVG_79 vs. AVG_21 } \\
\hline & & $\mathrm{FC}$ & Adjusted $p$ value & $\mathrm{FC}$ & Adjusted $p$ value & $\mathrm{FC}$ & Adjusted $p$ value \\
\hline P01877 & Ig alpha-2 chain $\mathrm{C}$ region & - & - & 2.13 & 0.0478 & 3.36 & 0.0033 \\
\hline P02763 & Alpha-1-acid glycoprotein 1 & - & - & 3.6 & 0.0041 & 2.98 & 0.0096 \\
\hline P24855 & Deoxyribonuclease-1 & - & - & 0.55 & 0.0209 & 0.5 & 0.0096 \\
\hline P26992 & Ciliary neurotrophic factor receptor alpha & - & - & 0.61 & 0.0078 & 0.56 & 0.0096 \\
\hline P25311 & Zinc-alpha-2-glycoprotein & - & - & 3.47 & 0.0041 & 2.4 & 0.0150 \\
\hline P19652 & Alpha-1-acid glycoprotein 2 & - & - & 2.58 & 0.0041 & 1.68 & 0.0239 \\
\hline Q6UXB8 & Peptidase inhibitor 16 & - & - & 2.73 & 0.0041 & 1.94 & 0.0396 \\
\hline P04217 & Alpha-1B-glycoprotein & - & - & 3.75 & 0.0213 & - & - \\
\hline P01833 & Polymeric immunoglobulin receptor & - & - & 0.52 & 0.0494 & - & - \\
\hline O75882 & Attractin & - & - & - & - & 0.6 & 0.0096 \\
\hline Q6GTX8 & $\begin{array}{l}\text { Leukocyte-associated immunoglobulin-like } \\
\text { receptor } 1\end{array}$ & - & - & - & - & 0.41 & 0.0004 \\
\hline P09486 & SPARC & - & - & - & - & 0.62 & 0.0117 \\
\hline P10451 & Osteopontin & - & - & - & - & 0.51 & 0.0239 \\
\hline Q9BY67 & Cell adhesion molecule 1 & - & - & - & - & 0.55 & 0.0265 \\
\hline P05060 & Secretogranin-1 & - & - & - & - & 0.38 & 0.0239 \\
\hline P00747 & Plasminogen & - & - & - & - & 0.51 & 0.0239 \\
\hline Q12805 & $\begin{array}{l}\text { EGF-containing fibulin-like extracellular } \\
\text { matrix protein } 1\end{array}$ & - & - & - & - & 1.51 & 0.0239 \\
\hline Q6UXG3 & CMRF35-like molecule 9 & - & - & - & - & 0.62 & 0.0239 \\
\hline P01860 & Ig gamma-3 chain $\mathrm{C}$ region & - & - & - & - & 0.55 & 0.0370 \\
\hline O95967 & $\begin{array}{l}\text { EGF-containing fibulin-like extracellular } \\
\text { matrix protein } 2\end{array}$ & - & - & - & - & 0.59 & 0.0301 \\
\hline P01133 & Pro-epidermal growth factor & - & - & - & - & 0.49 & 0.0361 \\
\hline P00450 & Ceruloplasmin & - & - & - & - & 1.55 & 0.0480 \\
\hline Q9NQ38 & Serine protease inhibitor Kazal-type 5 & - & - & - & - & 0.62 & 0.0480 \\
\hline P02760 & AMBP protein & - & - & - & - & 1.52 & 0.0396 \\
\hline
\end{tabular}

current understanding of the mechanisms of aging tissues, particularly in the context of cardiovascular tissue aging (Chen and Frangogiannis 2010). Physiologically, about one third of the cells in the myocardium comprise contractile tissue. The remaining tissue comprises connective tissue components, including fibroblasts and extracellular matrix proteins, such as collagen types I and III, elastin, and fibronectin (Lindsey et al. 2005).

It is thought that the disproportionate increase in the volume of non-contractile cells (predominantly fibroblasts) and an increased accumulation of collagen that is modified both in the intercellular and perivascular spaces may be responsible for ventricular dysfunction and disturbances in coronary hemodynamics (Weber 1989). These are characterized by an increase in extracellular matrix proteins in the components of connective tissue. Under physiological conditions, the metabolism of extracellular matrix proteins and collagen contents is stable. However, with arterial hypertension and the aging process, an imbalance occurs between collagen synthesis and degradation. With high blood pressure, there is an increase in both the synthesis and degradation of extracellular matrix components, with an emphasis on synthesis. In contrast, during the course of aging, these two activities are reduced, particularly with regard to protein degradation, which also leads to a reduced susceptibility of cardiovascular structures to injury and myocardial fibrosis.

These processes depend on the metabolic levels of cytokines and growth factors, including PDGF and VEGF. These are important for proper wound healing and regulate tissue regeneration. SPARC is a PDGF and VEGF antagonist that reduces their mitogenic activities. 

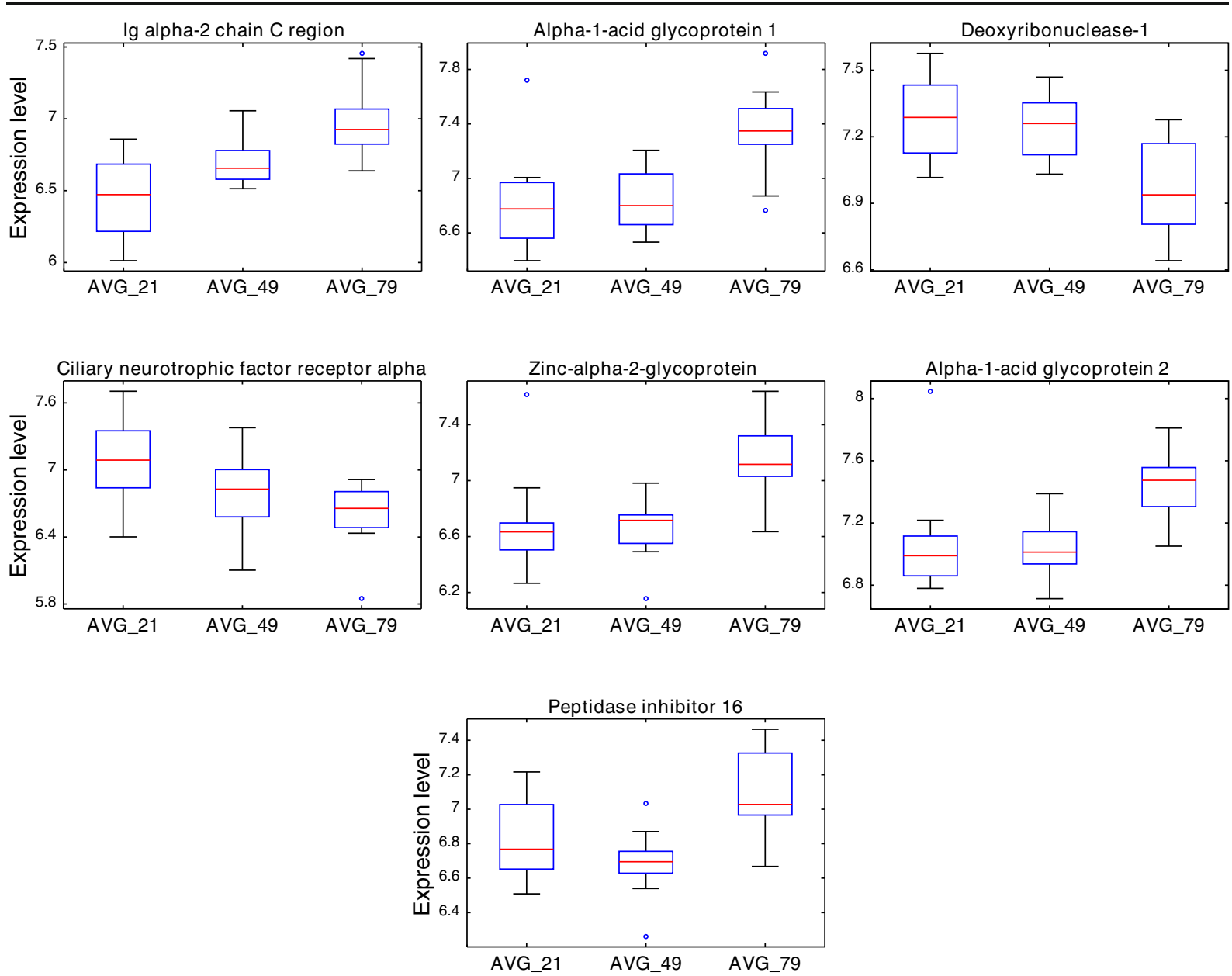

Fig. 2 Boxplots of seven urine proteins commonly identified as differentially expressed in two pair-wise comparisons: AVG_79 vs. AVG_21 and AVG_79 vs. AVG_49

A SPARC deficiency may be the cause of the excessive accumulation of extracellular matrix proteins, inadequate regulation of healing along with subsequent fibrosis, and reduced tissue susceptibility (Jørgensen et al. 2009). Also, reduced amounts of EGF-containing fibulin-like extracellular matrix protein 2 , which is necessary for the proper incorporation of elastin into extracellular matrix, may be a factor in old age for weakening blood vessels and skin connective tissues (cutis laxa) and result in greater tissue elasticity, which includes more collagen converted to elastin (Dasouki et al. 2007).

These processes may also be dependent on protease inhibitors. One of these is protease inhibitor 16 (PI16); the expression of which increased in our oldest group. In animal studies, increased PI 16 expression was associated with cardiac hypertrophy. PI16 is rapidly secreted following stimulation by serum in primary cardiomyocytes in vitro. In vivo, transgenic mice that overexpress PI16 in cardiomyocytes show normal heart function but have smaller hearts with hypotrophic cardiomyocytes. PI16 expression is enhanced in the hypertrophic and failing heart and suppresses cardiomyocyte growth (Frost and Engelhardt 2007). PI16 is a putative serine protease inhibitor that may also be used as a marker following prostatectomy for prostate cancer (Reeves et al. 2006).

Prothrombotic status

Our finding of reduced plasminogen expression in the urine of elderly people is in line with the reported decreases in the concentrations of plasminogen and plasminogen activator inhibitor in the blood of elderly people (Tait et al. 1992). This phenomenon can be explained by both a decrease in plasminogen activator inhibitor 

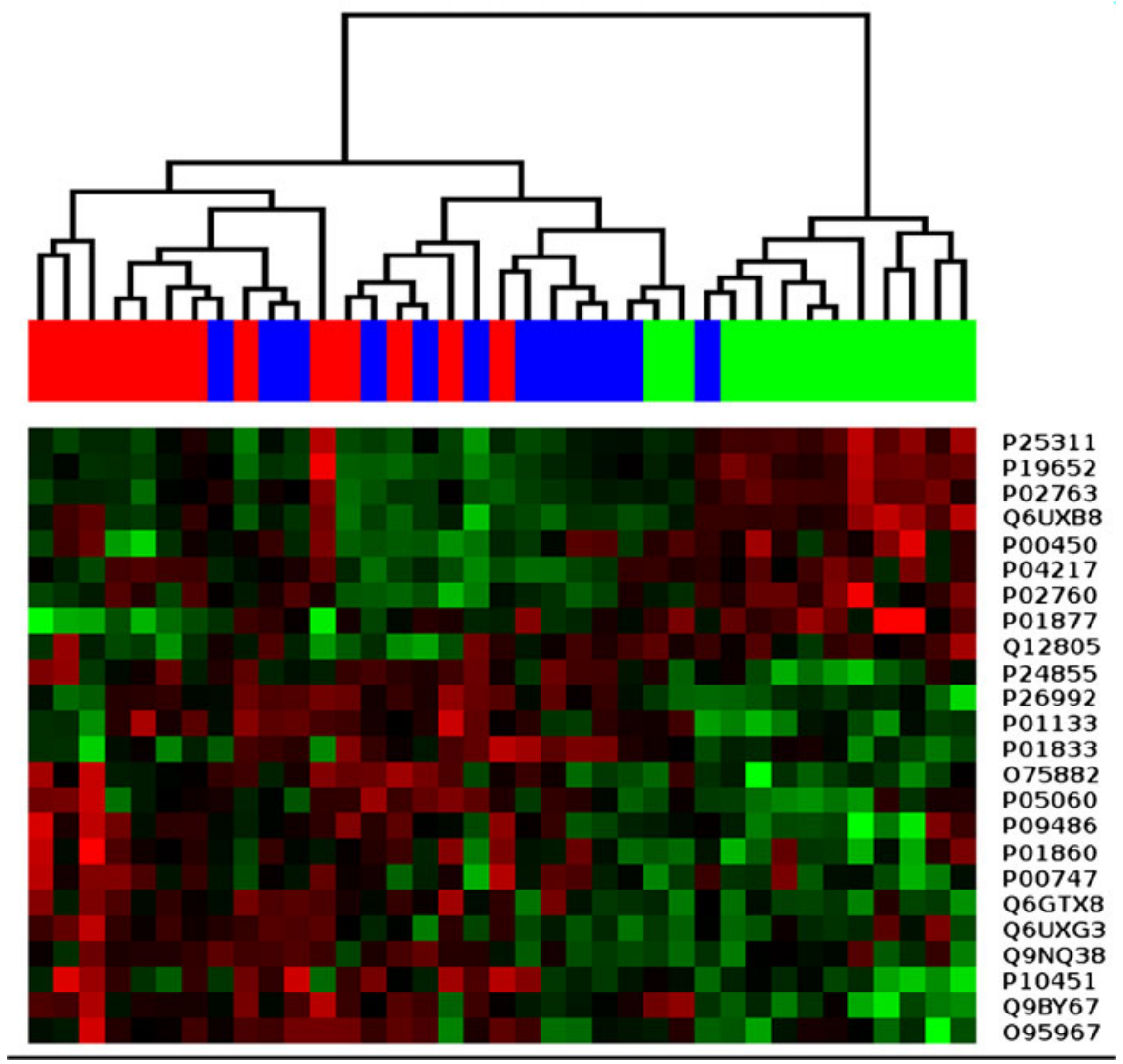

Fig. 3 Hierarchical clustering of urine samples from groups: AVG_21 (red, 13 samples), AVG_49 (blue, 12 samples), and $\mathrm{AVG}^{-} 79$ sample sets (green, 12 samples). Relative abundances

concentrations and an increased prothrombotic tendency in old age. Plasminogen is a major protein of the fibrinolytic system and has a high molecular weight. Its relatively high concentrations in serum and its long half-life would not support its role as regulating factor of fibrinolysis (Kołodziejczyk and Wachowicz 2009). These characteristics may qualify plasminogen as an aging marker as opposed to a plasminogen activator inhibitor, whose concentrations and half-life are low.

\section{Low-grade inflammation}

Proteins that could distinguish older people also have roles in inflammatory processes. Features of low-grade inflammation are found as a trait of aging in lung tissue (Meyer et al. 1998). The urine proteome of older people significantly differed from that of younger people for proteins that included alpha 1 acidic glycoprotein 1 and alpha 1 acidic glycoprotein 2 . These belong to acute of 24 proteins showing statistical significance (adjusted $p$ val$\mathrm{ue} \leq 0.05 ; \mathrm{FC} \geq 1.5$ ) in at least one pair-wise comparison between groups (Table 2) were used to generate the cluster tree

phase proteins, and their expression was increased. Serine protease inhibitor Kazal-type 5 is probably an important anti-inflammatory agent that protects mucous membranes and defends against the invasion of microorganisms. It also maintains the structure and function of the skin by regulating the activity of proteases that are responsible for the actions of defense and desquamationinvolved proteases (Jayakumar et al. 2005; Deraison et al. 2007). Its reduced levels may be indicative of subclinical inflammation in old age, as described for lung tissue (Meyer et al. 1998). This is in line with lower SPARC expression accompanied by a pro-fibrotic cytokine profile (Jørgensen et al. 2009).

\section{Dysregulation of the immune system}

Changes in the urinary proteome of the elderly may also reflect immune system disturbances. We found increased expression of $\operatorname{IgA}-1$ chain $\mathrm{C}$ region in the 
proteome of older people compared to younger people and reduced $\mathrm{IgG}-3$ chain $\mathrm{C}$ region. $\mathrm{IgA}$ is the major immunoglobulin class that is secreted into body fluids. IgA has a dual role of combating local infections and preventing foreign antigens' access to the general immune system (Corthésy 2013). IgG antibodies are the primary humoral defense mechanism in the context of acquired immunity (Senatorski and Hryniewiecka 2011). IgG binds antigens. This could be of importance, for example, in the direct neutralization of bacterial toxins or preventing virus penetration into cells. IgG3 activates the complement cascade, which supports the humoral arm of innate immunity (Quintana et al. 2008).

Another protein with reduced expression in the elderly belonged to the immunoglobulin superfamily leukocyte-associated immunoglobulin-like receptor 1 , also known as CD305 or LAIR1. This is found on peripheral mononuclear cells, such as T cells, NK cells, and $\mathrm{B}$ cells. As an inhibitor, it can regulate immune responses and prevent against the lysis of cells identified as self (Meyaard 2008).

\section{Autoimmune diseases}

Abnormal cell activation underlies autoimmune diseases (Tsukumo and Yasutomo 2004). One reason for systemic lupus is the presence of antinuclear autoantibodies. Their production may result from overexposure to nucleosomal antigens (dsDNA, native DNA). One hypothesis involves the reduced clearance of nucleosomal antigens and their accumulation in old age concomitant with a reduced activity of deoxyribonuclease1 in the blood, which is consistent with our research that demonstrated reduced expression of DNase-1 in the urine proteome of the elderly (Lachmann 2003). This also correlates with an increased incidence of systemic lupus erythematosus after 55 years of age.

Proteins with multidirectional effects

Another protein with reduced expression in the elderly is osteopontin (OPN), also known as bone sialoprotein I (Wang and Denhardt 2008). OPN plays an important role in bone remodeling as it anchors osteoclasts to the bone mineral matrix, which promotes the development of osteoclasts' corrugated surfaces that generate a low $\mathrm{pH}$ environment and locally initiate bone resorption. OPN in urine prevents the formation of urinary tract deposits. OPN also has immunological functions. By binding to receptors on lymphocytes, $\alpha 4 \beta 1, \alpha 9 \beta 1$, and $\alpha 9 \beta 4$, it affects the adhesion, migration, and survival of cells. A diverse range of these receptors' expression is found on macrophages, neutrophils, dendritic cells, and $\mathrm{T}$ and $\mathrm{B}$ cells.

As an immunomodulating agent, OPN has chemotactic properties for enhancing the recruitment of inflammatory cells. In animal experiments, inflammation is observed with prolonged persistence of macrophage clusters. OPN acts as an adhesion protein, which promotes cell adhesion and healing processes. In addition, OPN mediates cell activation and cytokine production and is a regulator of cellular apoptosis. It has effects similar to IL-10, a Th2 cytokine that exacerbates Th1 cell responses, and indirectly leads to increased production of antibodies by B lymphocytes. Thus, OPN plays a role in the pathogenesis of autoimmune diseases (rheumatoid arthritis, multiple sclerosis, AIH), cancer (lung, breast, colorectal cancers), and inflammatory diseases (glomerulonephritides, interstitial renal diseases, plaque formation) (Tachibana et al. 2012). Reduced OPN expression in older people could intensify allergy and atopic phenomena, as well as mitigate the course of autoimmune diseases, which is consistent with clinical observations (Jamroz-Wiśniewska et al. 2007).

Attractin (dipeptidyl peptidase IV (DP-IV)/CD26-like molecule) is a serine protease that has four copies of an EGF-like repeat motif and a C-type lectin domain and is involved in multiple intercellular communications and apoptosis, and regulates the effects of other cytokines and signaling molecules, including RANTES (Oravecz et al. 1997). It also inhibits TGF- $\beta$, thus contributing to extracellular matrix turnover, fibrosis, wound healing and tissue repair (Waller and Nicholson 2001), cell growth and proliferation, and anti-inflammatory properties. TGF- $\beta$ also plays an essential role in the pathogenesis of fibrotic diseases of the kidney, liver, and lung, as well as atherosclerosis, artery remodeling in hypertension and diabetes mellitus, rheumatoid arthritis, and cancer (Harris et al. 2007; Zegarska et al. 2006; Jain et al. 2000; Reinhold et al. 1997). Decreased DP-IV expression in the urinary proteome may explain the lack of TGF- $\beta$ inhibition and indicate a role for DP-IV and TGF- $\beta$ in the pathogenesis of aging and may explain its reduced ability to regulate the immune system as well as increased susceptibility to type 2 diabetes seen in the elderly (Laudes et al. 2010).

Secretogranin-1 (chromogranin B, secretoneurin) is a neuroendocrine protein involved in the formation of 
secretory granules in the pituitary, adrenal medulla, and hypothalamus (Natori et al. 1998). It also has chemotactic properties for monocytes, eosinophils (strength comparable to IL8), and endothelial cells. It is a known regulator of endothelial cell proliferation and is a potent angiogenic factor. What its reduced expression in the urine proteome in the elderly means is not known.

\section{Conclusions}

Characteristic changes in healthy elderly peoples' urine proteomes appear to reflect certain physiological processes associated with aging. We confirmed results from our previous experimental and clinical studies regarding the influence of the aging process on the activity of serum proteolytic enzymes and that the activities of individual proteolytic enzymes in the serum change with age (Paczek et al. 2008, 2009). Changes in the circulatory system and the immune system were particularly clearly represented. Detailed identification of these "protein trails" provides for creating a more "global picture" of the metabolic changes that occur in the elderly.

Our research may help to identify active and structural proteins whose levels change significantly during the natural process of aging. These results may help identify clinically important pathogenic pathways and build a multiscale model of human aging. This, in turn, could enable the development of intervention methods with the intent of slowing down the aging process.

Acknowledgments Support from the Polish Ministry of Science and Education grant no. 337/N-COST/2009/0 is kindly acknowledged. The excellent technical support of Agnieszka Fabijańska is also acknowledged. Tymon Rubel was supported by the European Social Fund through the project "Preparation and realization of Medical Physics speciality" (UDA-POKL 04.01.01-00-0004/09-00) at the Faculty of Physics of the Warsaw University of Technology.

Open Access This article is distributed under the terms of the Creative Commons Attribution License which permits any use, distribution, and reproduction in any medium, provided the original author(s) and the source are credited.

\section{References}

Anderson NG, Anderson NL, Tollaksen SL (1979) Proteins of human urine. I. Concentration and analysis by twodimensional electrophoresis. Clin Chem 25:1199-1210
Bakun M, Karczmarski J, Poznanski J, Rubel T, Rozga M, Malinowska A, Sands D, Hennig E, Oledzki J, Ostrowski J, Dadlez M (2009) An integrated LC-ESI-MS platform for quantitation of serum peptide ladders. Application for colon carcinoma study. Proteomics Clin Appl 3(8):932-946

Barratt J, Topham P (2007) Urine proteomics: the present and future of measuring urinary protein components in disease. CMAJ 177:361-368

Benjamini Y, Hochberg Y (1995) Controlling the false discovery rate: a practical and powerful approach to multiple testing. $\mathrm{J}$ R Stat Soc B 57:289-300

Bulpitt CJ, Shipley MJ, Broughton PM, Fletcher AE, Markowe HL, Marmot MG, Semmence A, Rose G (1994) The assessment of biological age: a report from the Department of Environment Study. Aging (Milano) 6(5):181-191

Chen W, Frangogiannis NG (2010) The role of inflammatory and fibrogenic pathways in heart failure associated with aging. Heart Fail Rev 15(5):415-422

Corthésy B (2013) Role of secretory IgA in infection and maintenance of homeostasis. Autoimmun Rev 12:661-665

Cowdry EV (1942) Problems of ageing: biological and medical aspects, 2nd edn. Williams \& Wilkins, Baltimore

Dasouki M, Markova D, Garola R, Sasaki T, Charbonneau NL, Sakai LY, Chu ML (2007) Compound heterozygous mutations in fibulin-4 causing neonatal lethal pulmonary artery occlusion, aortic aneurysm, arachnodactyly, and mild cutis laxa. Am J Med Genet A 143A(22):2635-2641

de los Campos G, Klimentidis YC, Vazquez AI, Allison DB (2012) Prediction of expected years of life using wholegenome markers. PLoS One 7(7):e40964. doi:10.1371/ journal.pone.0040964, Epub 2012 Jul 25

Deraison C, Bonnart C, Lopez F, Besson C, Robinson R, Jayakumar A, Wagberg F, Brattsand M, Hachem JP, Leonardsson G, Hovnanian A (2007) LEKTI fragments specifically inhibit KLK5, KLK7, and KLK14 and control desquamation through a $\mathrm{pH}$-dependent interaction. Mol Biol Cell 18(9):3607-3619

Frost RJ, Engelhardt S (2007) A secretion trap screen in yeast identifies protease inhibitor 16 as a novel antihypertrophic protein secreted from the heart. Circulation 116(16):1768-1775

Harris S, Coupes BM, Roberts SA, Roberts IS, Short CD, Brenchley PE (2007) TGF-beta1 in chronic allograft nephropathy following renal transplantation. J Nephrol 20(2):177-185

Jain S, Furness PN, Nicholson ML (2000) The role of transforming growth factor beta in chronic renal allograft nephropathy. Transplantation 69(9):1759-1766

Jamroz-Wiśniewska A, Wójcicka G, Horoszewicz K, Bełtowski J (2007) Liver X receptors (LXRs). Part II: non-lipid effects, role in pathology, and therapeutic implications. Postepy Hig Med Dosw (Online) 61:760-785

Jayakumar A, Kang Y, Henderson Y, Mitsudo K, Liu X, Briggs K, Wang M, Frederick MJ, El-Naggar AK, Bebök Z, Clayman GL (2005) Consequences of C-terminal domains and N-terminal signal peptide deletions on LEKTI secretion, stability, and subcellular distribution. Arch Biochem Biophys 435(1):89-102

Jørgensen LH, Petersson SJ, Sellathurai J, Andersen DC, Thayssen S, Sant DJ, Jensen CH, Schrøder HD (2009) Secreted protein acidic and rich in cysteine (SPARC) in human skeletal muscle. J Histochem Cytochem 57(1):29-39 
Julian BA, Wittke S, Haubitz M, Zurbig P, Schiffer E, McGuire BM, Wyatt RJ, Novak J (2007) Urinary biomarkers of IgA nephropathy and other IgA-associated renal diseases. World J Urol 25:467-476

Käll L, Storey JD, MacCoss MJ, Noble WS (2008) Assigning significance to peptides identified by tandem mass spectrometry using decoy databases. J Proteome Res 7:29-34

Kistler AD, Mischak H, Poster D, Dakna M, Wüthrich RP, Serra AL (2009) Identification of a unique urinary biomarker profile in patients with autosomal dominant polycystic kidney disease. Kidney Int 76(1):89-96

Kołodziejczyk J, Wachowicz B (2009) Dysfunction of fibrinolysis as a risk factor of thrombosis. Pol Merkur Lekarski 27(160):341-345

Lachmann PJ (2003) Lupus and desoxyribonuclease. Lupus 12(3):202-206

Laudes M, Oberhauser F, Schulte DM, Schilbach K, Freude S, Bilkovski R, Schulz O, Faust M, Krone W (2010) Dipeptidylpeptidase 4 and attractin expression is increased in circulating blood monocytes of obese human subjects. Exp Clin Endocrinol Diabetes 118(8):473-477

Lindsey ML, Goshorn DK, Squires CE, Escobar GP, Hendrick JW, Mingoia JT, Sweterlitsch SE, Spinale FG (2005) Agedependent changes in myocardial matrix metalloproteinase/ tissue inhibitor of metalloproteinase profiles and fibroblast function. Cardiovasc Res 66(2):410-419

Lipsitz LA, Goldberger AL (1992) Loss of 'complexity' and aging. Potential applications of fractals and chaos theory to senescence. JAMA 267:1806-1809

Martin JE, Sheaff MT (2007) The pathology of ageing: concepts and mechanisms. J Pathol 211(2):111-113

Meyaard L (2008) The inhibitory collagen receptor LAIR-1 (CD305). J Leukoc Biol 83(4):799-803

Meyer KC, Rosenthal NS, Soergel P, Peterson K (1998) Neutrophils and low-grade inflammation in the seemingly normal aging human lung. Mech Ageing Dev 104(2):169-181

Michel DM, Kelly CJ (1998) Acute interstitial nephritis. J Am Soc Nephrol 9(3):506-515

Mikula M, Gaj P, Dzwonek K, Rubel T, Karczmarski J, Paziewska A, Dzwonek A, Bragoszewski P, Dadlez M, Ostrowski J (2010) Comprehensive analysis of the palindromic motif TCTCGCGAGA: a regulatory element of the HNRNPK promoter. DNA Res 17:245-260

M'Koma AE, Blum DL, Norris JL, Koyama T, Billheimer D, Motley S, Ghiassi M, Ferdowsi N, Bhowmick I, Chang SS, Fowke JH, Caprioli RM, Bhowmick NA (2007) Detection of pre-neoplastic and neoplastic prostate disease by MALDI profiling of urine. Biochem Biophys Res Commun 353:829-834

Mosley K, Tam FW, Edwards RJ, Crozier J, Pusey CD, Lightstone L (2006) Urinary proteomic profiles distinguish between active and inactive lupus nephritis. Rheumatology (Oxford) 45:1497-1504

Natori S, King A, Hellwig A, Weiss U, Iguchi H, Tsuchiya B, Kameya T, Takayanagi R, Nawata H, Huttner WB (1998) Chromogranin B (secretogranin I), a neuroendocrineregulated secretory protein, is sorted to exocrine secretory granules in transgenic mice. EMBO J 17(12):3277-3289

Oravecz T, Pall M, Roderiquez G, Gorrell MD, Ditto M, Nguyen NY, Boykins R, Unsworth E, Norcross MA (1997) Regulation of the receptor specificity and function of the chemokine RANTES (regulated on activation, normal $\mathrm{T}$ cell expressed and secreted) by dipeptidyl peptidase IV (CD26)mediated cleavage. J Exp Med 186(11):1865-1872

Paczek L, Michalska W, Bartlomiejczyk I (2008) Trypsin, elastase, plasmin and MMP-9 activity in the serum during the human ageing process. Age Ageing 37(3):318-323

Paczek L, Michalska W, Bartlomiejczyk I (2009) Proteolytic enzyme activity as a result of aging. Aging Clin Exp Res 21(1):9-13

Pavik I, Jaeger P, Ebner L, Poster D, Krauer F, Kistler AD, Rentsch K, Andreisek G, Wagner CA, Devuyst O, Wüthrich RP, Schmid C, Serra AL (2012) Soluble klotho and autosomal dominant polycystic kidney disease. Clin J Am Soc Nephrol $7(2): 248-257$

Pisitkun T, Johnstone R, Knepper MA (2006) Discovery of urinary biomarkers. Mol Cell Proteomics 5:1760-1771

Quintana FJ, Solomon A, Cohen IR, Nussbaum G (2008) Induction of IgG3 to LPS via Toll-like receptor 4 co-stimulation. PLoS One 3(10):e3509

Reeves JR, Dulude H, Panchal C, Daigneault L, Ramnani DM (2006) Prognostic value of prostate secretory protein of 94 amino acids and its binding protein after radical prostatectomy. Clin Cancer Res 12(20 Pt 1):6018-6022

Reinhold D, Bank U, Bühling F, Täger M, Born I, Faust J, Neubert K, Ansorge S (1997) Inhibitors of dipeptidyl peptidase IV (DP IV, CD26) induces secretion of transforming growth factor-beta 1 (TGF-beta 1) in stimulated mouse splenocytes and thymocytes. Immunol Lett 58(1):29-35

Rich MW, Crecelius CA (1990) Incidence, risk factors, and clinical course of acute renal insufficiency after cardiac catheterization in patients 70 years of age or older. A prospective study. Arch Intern Med 150(6):1237-1242

Senatorski G, Hryniewiecka E (2011) Application of intravenous immunoglobulin preparations (IVIGs) in organ transplantation. Pol Merkur Lekarski 30(180):417-422

Tachibana H, Ogawa D, Matsushita Y, Bruemmer D, Wada J, Teshigawara S, Eguchi J, Sato-Horiguchi C, Uchida HA, Shikata K, Makino H (2012) Activation of liver X receptor inhibits osteopontin and ameliorates diabetic nephropathy. J Am Soc Nephrol 23(11):1835-1846

Tait RC, Walker ID, Conkie JA, Islam SIAM, MacCall F, Mitchell R, Davidson JF (1992) Plasminogen levels in healthy volunteers. Influence of age, sex, smoking and oral contraceptives. Thromb Haemost 68(5):506-510

Tsukumo S, Yasutomo K (2004) DNaseI in pathogenesis of systemic lupus erythematosus. Clin Immunol 113(1):14-18

Tyan YC, Guo HR, Liu CY, Liao PC (2006) Proteomic profiling of human urinary proteome using nano-high performance liquid chromatography/electrospray ionization tandem mass spectrometry. Anal Chim Acta 579:158-176

van Eyk JE, Dunn MJ (2008) Clinical proteomics from diagnosis to therapy. Wiley, Weinheim

Varghese SA, Powell TB, Budisavljevic MN, Oates JC, Raymond JR, Almeida JS, Arthur JM (2007) Urine biomarkers predict the cause of glomerular disease. J Am Soc Nephrol 18:913-922

vB Hjelmborg J, Iachine I, Skytthe A, Vaupel JW, McGue M, Koskenvuo M, Kaprio J, Pedersen NL, Christensen K (2006) Genetic influence on human lifespan and longevity. Hum Genet 119(3):312-321

Veldhuis JD (1997) Altered pulsatile and coordinate secretion of pituitary hormones in aging: evidence of feedback disruption. Aging (Milano) 9(4 Suppl):19-20 
Waller JR, Nicholson ML (2001) Molecular mechanisms of renal allograft fibrosis. Br J Surg 88(11):1429-1441

Wang KX, Denhardt DT (2008) Osteopontin: role in immune regulation and stress responses. Cytokine Growth Factor Rev 19(5-6):333-345

Weber KT (1989) Cardiac interstitium in health and disease: the fibrillar collagen network. J Am Coll Cardiol 13(7): $1637-1652$

Weissinger EM, Wittke S, Kaiser T, Haller H, Bartel S, Krebs R, Golovko I, Rupprecht HD, Haubitz M, Hecker H, Mischak H, Fliser D (2004) Proteomic patterns established with capillary electrophoresis and mass spectrometry for diagnostic purposes. Kidney Int 65:2426-2434

Yao X, Li H, Leng SX (2011) Inflammation and immune system alterations in frailty. Clin Geriatr Med 27(1):79-87

Zegarska J, Paczek L, Pawlowska M, Wyczalkowska A, Michalska W, Ziolkowski J, Gorski A, Rowinski W, Kosieradzki M, Kwiatkowski A, Gornicka B, ZiarkiewiczWroblewska B (2006) Increased mRNA expression of transforming growth factor beta in the arterial wall of chronically rejected renal allografts in humans. Transplant Proc 38(1):115-118 